\title{
Heterogeneity Impact on SAGD Process Performance in Mobile Heavy Oil Reservoirs
}

\author{
M. Le Ravalec ${ }^{1}$, C. Morlot ${ }^{2}$, R. Marmier ${ }^{2}$ and D. Foulon² \\ 1 Institut français du pétrole, IFP, 1-4 avenue de Bois-Préau, 92852 Rueil-Malmaison Cedex - France \\ 2 TOTAL, 2 place de la Coupole, 92078 La Défense Cedex - France \\ e-mail: mickaele.le-ravalec@ifp.fr - celia.morlo@łtotal.com - remy.marmier@total.com -david.foulon@total.com
}

\begin{abstract}
Résumé - Impact des hétérogénéités sur la production d'huiles lourdes mobiles par SAGD L'augmentation de la demande en pétrole et l'existence de réserves conséquentes en huiles lourdes et bitumes vont motiver, dans les prochaines décennies, un effort important pour développer les réservoirs non conventionnels. Dans ce cadre, la production par drainage gravitaire soutenu par une injection de vapeur (SAGD) est une technique très prometteuse pour extraire les huiles lourdes des réservoirs épais et de forte perméabilité. Les tests pilotes conduits sur champ à ce jour ont souligné l'influence des hétérogénéités sur le développement de la chambre induite par l'injection de vapeur. Cette étude présente les résultats d'une analyse numérique visant à apprécier l'impact des hétérogénéités sur la quantité d'huile produite par SAGD dans des réservoirs contenant des huiles lourdes mobiles. Une population de modèles de réservoir contenant $0,10,15$ ou $20 \%$ d'argile a été générée aléatoirement. Puis, la production par SAGD a été simulée pour chacun de ces modèles. Il apparaît que l'influence des lentilles d'argile dépend de leurs positions par rapport aux paires de puits, la configuration la plus préjudiciable étant celle où les lentilles argileuses se situent entre le puits injecteur et le puits producteur. En outre, on observe qu'on obtient la moitié, le tiers et le quart seulement du volume produit cumulé pour le modèle homogène après 3 ans de SAGD lorsque les proportions d'argile sont respectivement de 10,15 et $20 \%$. Parallèlement, on montre que le CSOR passe de 2 pour le modèle homogène à 3 pour les modèles avec $20 \%$ d'argile.
\end{abstract}

\begin{abstract}
Heterogeneity Impact on SAGD Process Performance in Mobile Heavy Oil Reservoirs - The increasing oil demand and the significant amount of heavy oil/bitumen reserves will motivate a huge effort on the development of heavy oil reservoirs in the next decades. Within this framework, Steam Assisted Gravity Drainage (SAGD) is a very promising technique to produce heavy oil from thick and high permeability reservoirs. The small scale field tests conducted up to now highlighted the influence of heterogeneities on the development of the steam chamber involved in SAGD. This work presents a numerical investigation of the effects of heterogeneity on SAGD performance when applied to produce mobile heavy oil. A set of reservoir models is randomly generated with $0,10,15$ and $20 \%$ of shale and a statistical analysis is performed to quantify the impact of shale distribution on oil production and SAGD efficiency. It is shown that the influence of shale baffles depends on their locations relatively to well pairs, the most detrimental ones being located between the injector and producer. In addition, we observe that 1/2,1/3 and 1/4 only of the cumulative oil volume produced for the homogeneous model after 3 years of SAGD process are recovered when shale proportions are 10,15 and 20\% and that CSOR evolves from 2 for the homogeneous model to 3 for the models with $20 \%$ of shale.
\end{abstract}




\section{INTRODUCTION}

The resources of heavy oil in the world are more than twice of those conventional light crude oil. Large quantities of heavy crudes have been discovered in the Americas including Canada, Venezuela and California. Heavy crude oil or extra heavy oil is any type of crude oil, which does not flow easily due to its high viscosity. Typical API gravity values are less than $20^{\circ}$. When heavy oil reservoirs are too deep to support economic surface mining operations, some form of an in-situ recovery is required to produce oil. For many decades, heavy oils, when mobile, were produced by primary production leading to low recovery factors of about $10 \%$. In 1959, steam flooding was first tested by Shell in the Venezuela Mene Grande tar sand field, which fortuitously motivates the development of Cyclic Steam Stimulation (CSS). This experiment contributed to significantly improve oil production. Then, numerous in-situ technologies have been developed that use thermal energy to heat heavy oils and make them flow to wellbores. These include steam injection processes through vertical or horizontal wells such as CSS, steam drive (SD), Pressure Cyclic Steam Drive (PCSD), Horizontal Alternate Steam Drive (HASD) and Steam Assisted Gravity Drainage (SAGD).

The SAGD process was introduced by Butler (1991). It involves drilling two parallel horizontal wells at the bottom of a thick, usually unconsolidated, sandstone reservoir: a production well and a steam injection well located 5 to $10 \mathrm{~m}$ above it. The principle is to heat the oil sands between the wells until the heavy oil is mobilized and pressure communication is established. Steam, injected through the top well, forms a vapor phase chamber that grows within the oil formation. The injected steam reaches the edges of the depletion chamber and delivers latent heat to the heavy oil saturated sand. Then, the viscosity of the heated oil decreases so that oil drains under the action of gravity within and along the edges of the steam chamber towards the production well. In the initial stages of the process, the chamber grows vertically. After the chamber reaches the top of the reservoir, it grows laterally. The flow rate of the production well is controlled so that the bottom hole temperature of the produced fluids is a few degrees Celsius below the saturated steam temperature at the operating pressure. This temperature differential is referred to as "subcool". The subcool level impacts the level of the liquid that builds up above the horizontal producer (Edmunds, 1998). An optimum subcool corresponds to a liquid level localized between the injector and the producer wells. The steam chamber cones down below the injection well, but not into the producer well.

The SAGD recovery process was first field-tested at the Underground Test Facility (UTF) in Fort McMurray, Canada (Edmunds et al., 1989), where the bitumen is completely immobile at initial reservoir conditions. This technology applied successfully to UTF, may be because of the relative homogeneity of the geological formation. Oil rates in excess of $100 \mathrm{~m}^{3} / \mathrm{d}$ have been achieved with $500 \mathrm{~m}$ long well pairs. On other fields, 4D seismic results show that fractions of wellbores do not have steam chamber development along their length due to geological heterogeneity (Zhang et al., 2005). Jimenez (2008) reviewed a large database of SAGD operations in Canada. He pointed out the strong impact of heterogeneities on SAGD performance referring to PetroCanada's MacKayRiver. MacKayRiver is currently the most efficient SAGD operation in Canada in terms of volumes of steam injected and oil produced. It contains 4 contiguous pads, named A to D from East to West, which have been operated for the same amount of time and have gone through the same steam shortages. Pads B and C had roughly the same performance while A and D were not as good. Jimenez (2008) explained that these differences are due to geologies and thicknesses. Pad A is the thinnest and its dominant facies is a breccia rather than a clean sand. Pad C is very thick with no apparent shale baffles. For pad D, the reservoir is thinner at the heel. Albahlani and Babadagli (2008) compiled the records produced about SAGD over the last three decades and pointed out the strengths and weaknesses in this process. Permeability is one of the most critical reservoir parameters to SAGD processes. Shale interbeds, whose permeability is almost zero, prevent the steam chamber from expanding vertically (Fig. 1) and have profound effects on well productivity, oil recovery and Cumulative Steam-Oil Ratio (CSOR). The CSOR refers to the cumulative steam volume (expressed as cold water equivalent) injected divided by the cumulative oil volume produced: it is used to asses the economics of steam injection applications as it gives the amount of energy required to produce one barrel of oil. Typically, a process is considered to be efficient when its CSOR is between 2 and 3 or lower. The understanding of the impact of heterogeneity on SAGD performance motivated different studies. Kisman and Yeung (1995) conducted a numerical study to investigate the sensitivity of SAGD process to flow barriers. Overall, they show that the effect of the barriers on performance was small unless these barriers are both continuous and stable under steam conditions. Although barriers prevent the chamber from growing up, they make it progress further laterally. This phenomenon is consistent with the results reported by Yang and Butler (1992). They did an extensive laboratory study and investigated a number of geometries. They showed that as long as heat can transfer upward and there is a small gap between shale interbeds, heavy oil can be drained. The small gap is required to provide a good vertical communication. These authors concluded that discontinuous mudstones delay oil recovery, but do not impair ultimate recovery. On the other hand, Barillas et al. (2006) showed that heterogeneity and vertical permeability have a major influence on oil recovery. Such studies were extended to a stochastic framework by Chen et al. (2007). These authors identified two flow regions, 

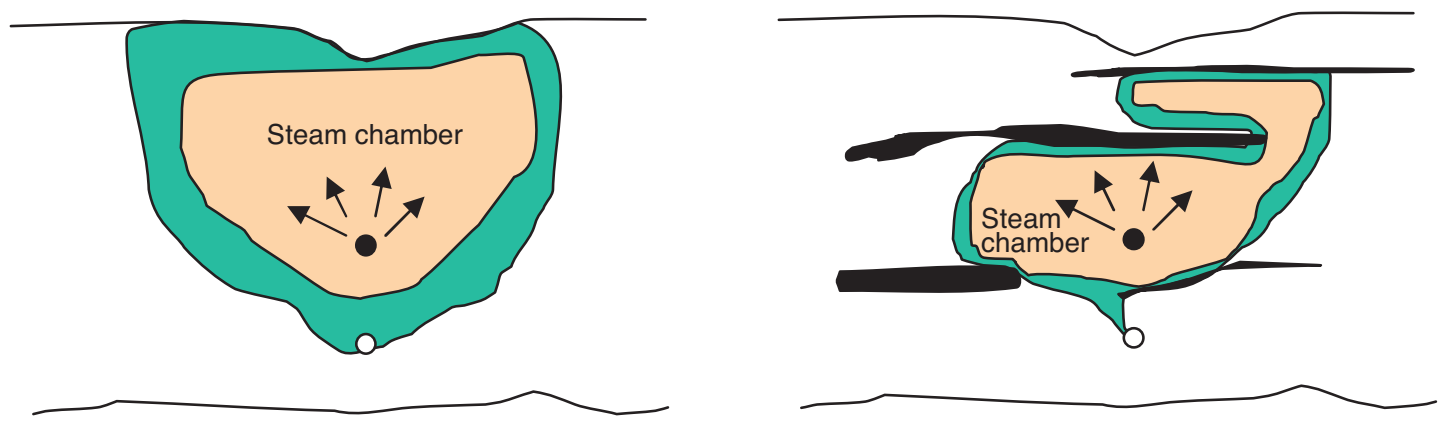

Figure 1

Left: steam chamber development in a homogeneous reservoir.

Right: steam chamber development in a reservoir with shale baffles of limited extent.

the near well region and the above well region. They concluded that thermal recovery is very sensitive to short heterogeneities in the near well region and to long heterogeneities in the above well region. They also showed that oil recovery is more or less the same for shaly-sand percentages of 10 and $30 \%$. The impact of shale baffles was obvious only for a shaly-sand percentage of $50 \%$.

We want to investigate the performance of the SAGD process to produce an unconsolidated sandstone reservoir containing mobile heavy oil. The target sand-shale proportions are in the range $10-20 \%$, which is the domain with no clear conclusion following the investigative work of Chen $e t$ al. (2007). The objective of this study is to quantify the impact of shale interbeds on oil recovery and CSOR based upon a set of numerical experiments performed in a stochastic framework. The numerical reservoir model is introduced in the first section. Then, we consider a homogeneous model that we use as a base line. The last section is dedicated to the analysis of the impact of shale distribution and volume fraction on oil production.

\section{NUMERICAL RESERVOIR MODEL}

Flow simulations are performed on three-dimensional reservoir models using the thermal, compositional simulator model STARS, which accounts for reservoir temperature changes and phase changes (Computer Modeling Group Ltd., 2005).

The 3D reservoir model represents a generic extra heavyoil formation. It is kept as simple as possible to highlight the impact of shale heterogeneities. The reservoir is $300 \mathrm{~m}$ deep with a pay zone thickness of $30 \mathrm{~m}$ and no active aquifer. It consists of two facies: clean sands of $30 \%$ porosity and $15 \mathrm{D}$ permeability and shales of $1 \%$ porosity and $1 \mathrm{mD}$ permeability. The ratio of vertical permeability to horizontal permeability is 0.2 for sand and 0.001 for shale. The grid system is Cartesian with local grid refinement immediately around the $500 \mathrm{~m}$ long wells. The operating system is described in the following subsection. Thus, the grid consists of $61 \times 55 \times 30$ grid blocks. Grid block dimension is $3 \times 10 \times 1 \mathrm{~m}^{3}$ in the middle of the reservoir, then it is progressively reduced to $1 \times 10 \times 1 \mathrm{~m}^{3}$ in the vicinity of the wells. Grid dimensions were selected based upon a preliminary sensitivity analysis performed with a homogeneous clean sand reservoir model. Reducing further block size did not significantly change flow responses.

Initial oil and water saturations in the pay zone are 0.8 and 0.2 , respectively. The initial reservoir temperature and pressure are $46^{\circ} \mathrm{C}$ and 41 bars. The PVT accounts for 3 components: water, heavy fraction and dissolved gas. Viscosity variations against temperature are given in Table 1 (Rodriguez et al., 2003). The transfer of the PVT to STARS involves a slightly non-linear mixing for oil viscosities, which emphasizes the impact of dissolved gas. In such conditions, initial oil viscosity at reservoir conditions is about $2500 \mathrm{cP}$. Relative permeability curves are built from the Corey model with an exponent of 2 . Saturation endpoints are 0.2 and 0.8 while the corresponding relative permeability endpoints are 0 and 1 . Oil gravity is $8^{\circ}$ API.

The extra heavy oil considered is mobile, which makes natural depletion production very suitable because of its low cost. However, the associated recovery factors are low and can be even lower in the presence of aquifers. A typical ultimate cold recovery factor in Venezuela is in the order of $7 \%$. Conversion to a thermal production mechanism allows for improving oil recovery. We move to a SAGD recovery process when natural depletion induces a reservoir pressure decrease from 41 bars (initial reservoir pressure) to 35 bars. This pressure level corresponds to about $2 / 3$ of the ultimate cold recovery factor. 
For simulating the SAGD process, two half well pairs are placed on the boundary of the grid (Fig. 2). This configuration was selected so as to investigate also steam chamber coalescence. The horizontal producers are $500 \mathrm{~m}$ long and located $5 \mathrm{~m}$ above the bottom of the reservoir. The horizontal injectors, of the same length, are drilled $7 \mathrm{~m}$ above the producers. The horizontal spacing between well pairs is $150 \mathrm{~m}$. As stated above, the reservoir is assumed to be first depleted till 35 bars before starting SAGD. Then, steam is injected at a maximum pressure of 41 bars so that pressure never exceeds the initial reservoir pressure. We also picked a constraint about the maximum rate of steam injected, expressed as water equivalent, which cannot exceed 300 $\mathrm{m}^{3} /$ day. The quality and temperature of the injected steam are 0.9 and $255^{\circ} \mathrm{C}$, respectively. To mimic steam trap conditions, producers are operated with constraints on the rate of steam produced. This one cannot be more than $1 \mathrm{~m}^{3} /$ day (expressed as cold water equivalent). When this constraint is violated, the production rate is reduced. In addition, minimal pressures in producers are set to 10 bars. Producing a well pair gets too costly after a period of about 10 years. Thus, after 10 years of SAGD production, we move to a blow down for 7 years. Blow down was preferred to gradual pressure depletion because the heavy oil produced is mobile.

TABLE 1

Oil viscosity against temperature $\mathrm{T}$ for heavy component and dissolved gas

\begin{tabular}{c|c|c}
\hline$T\left({ }^{\circ} \mathrm{C}\right)$ & Heavy component viscosity $(\mathrm{cP})$ & Dissolved gas viscosity $(\mathrm{cP})$ \\
\hline 5 & $1.6410^{6}$ & 4307.41 \\
\hline 15 & $2.2910^{5}$ & 603.819 \\
\hline 25 & $5.4510^{4}$ & 143.4324 \\
\hline 30 & $3.0010^{4}$ & 78.974 \\
\hline 48 & 5340 & 14.05738 \\
\hline 50 & 5340 & 14.05738 \\
\hline 65 & 1600 & 4.21195 \\
\hline 100 & 150 & 0.39487 \\
\hline 150 & 17 & 0.04475195 \\
\hline 200 & 6 & 0.0157948 \\
\hline 250 & 2.7 & 0.00710766 \\
\hline 300 & 1.8 & 0.00473844 \\
\hline
\end{tabular}

\section{BASE CASE MODEL}

We first consider a sand reservoir without any shale heterogeneity. Produced and injected rates for a single well are displayed against time in Figure 3. Two distinct periods are distinguished during the SAGD phase. During the first 2 years, oil production rate increases up to $230 \mathrm{~m}^{3} /$ day as

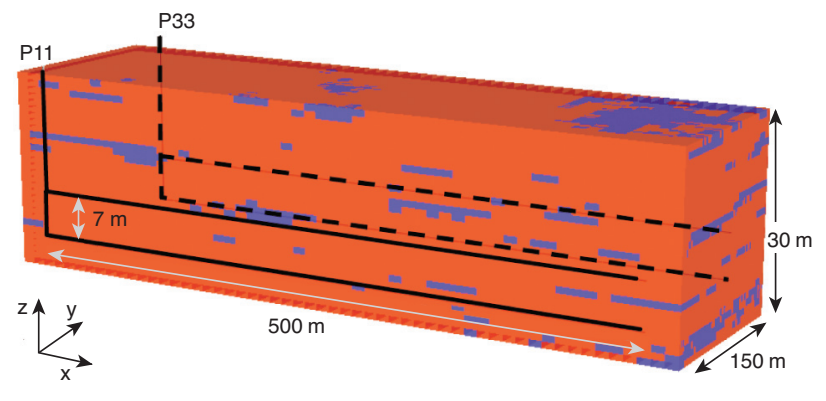

Figure 2

Well layout.

steam chamber grows vertically (Fig. 4). Then, oil rate gradually decreases as steam chamber expands laterally (Fig. 4). Steam chamber expansion is uniform all along well pairs. In addition, comparing temperature (Fig. 4), water fraction in gas (Fig. 5) and ternary diagram evolutions shows that chamber coalescence occurs 9 years after the beginning of injection.

The SAGD phase is stopped after 10 years because oil rate gets too small to make production economic. At this time, the CSOR is 2.4. The following blow down period is characterized by a pressure decrease and a gas rate increase. At the bubble point pressure, gas bubbles form or nucleate. They expand with continued decreasing pressure.

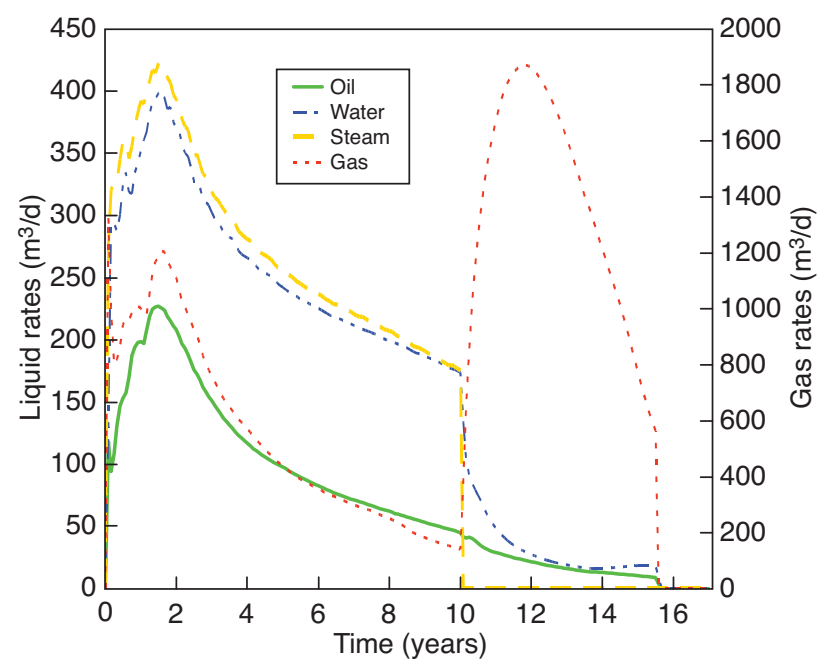

Figure 3

Oil, gas, water rates and injected steam rate simulated for a single well for the homogeneous baseline reservoir model. 

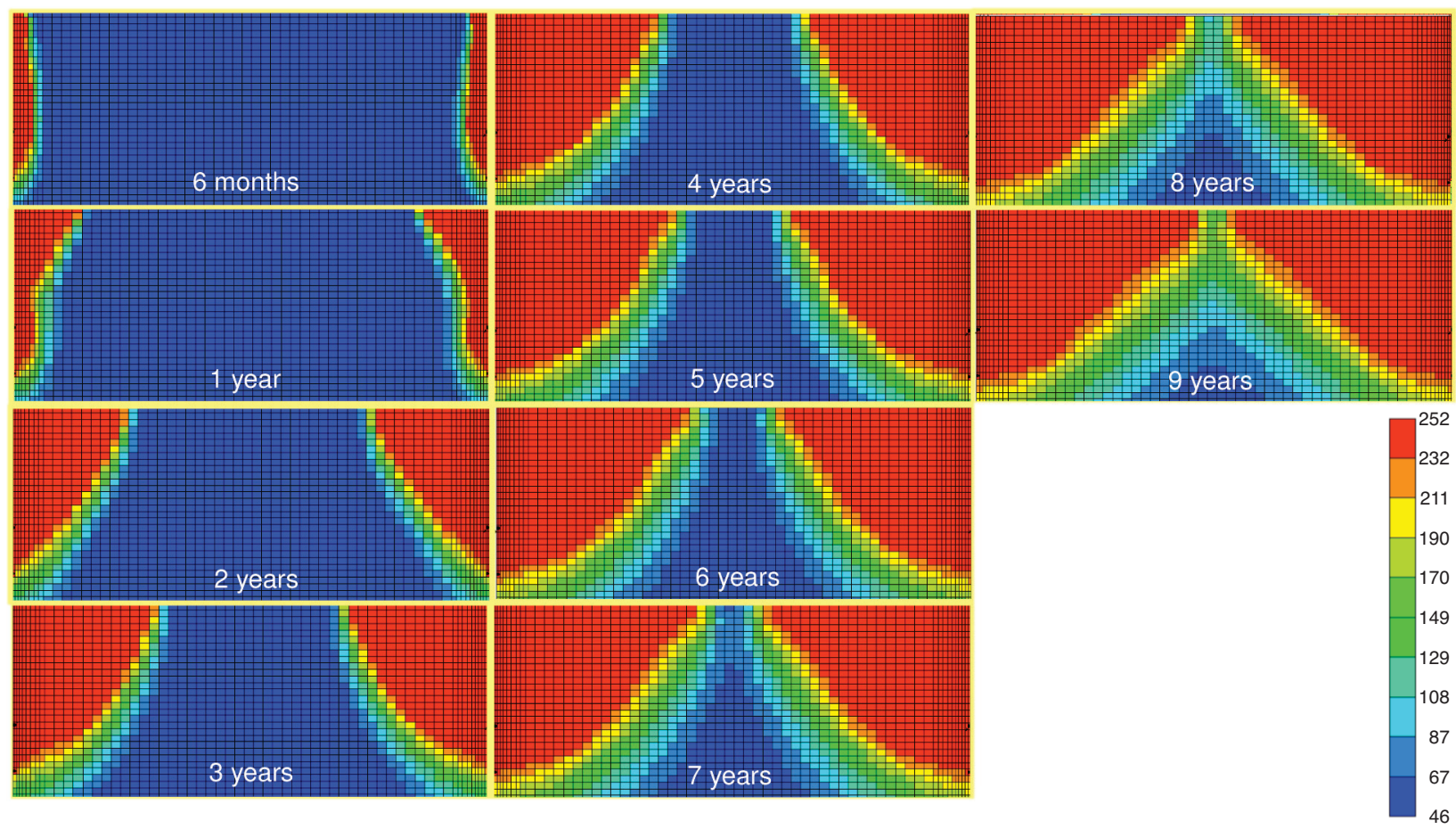

Figure 4

Evolution of the temperature chamber against time in cross-sections perpendicular to wells. Temperature is given in ${ }^{\circ} \mathrm{C}$.

\section{EFFECTS OF HETEROGENEITY ON SAGD PERFORMANCE AND DISCUSSION}

\subsection{Heterogeneity Modeling}

Heterogeneity is included in the reservoir by randomly generating two-facies realizations from sequential indicator simulation (Goovaerts, 1997). The variogram selected to describe shaly heterogeneities is exponential. Correlation lengths are $100 \mathrm{~m}$ and $2 \mathrm{~m}$ in the horizontal and vertical directions, respectively. The shale proportions of interest, assumed to be stationary, are 10,15 and $20 \%$. This range is typical of the values that can be found in Venezuela.

For each proportion value, 10 distinct equiprobable realizations are drawn. In such conditions, lateral continuity of shales is controlled by their proportions. Examples are displayed in Figure 6. Facies proportion can be interpreted in terms of occupancy probability of grid blocks. When it increases, shale baffles or clusters tend to grow and merge. At a particular value of the occupancy probability, known as percolation threshold, one cluster dominates and becomes "infinitely" large. The threshold value for a simple cubic grid is about 0.3 (Stauffer and Aharony, 1994). Thus, there is no shale barrier spanning the entire grid in the realizations considered in this work.

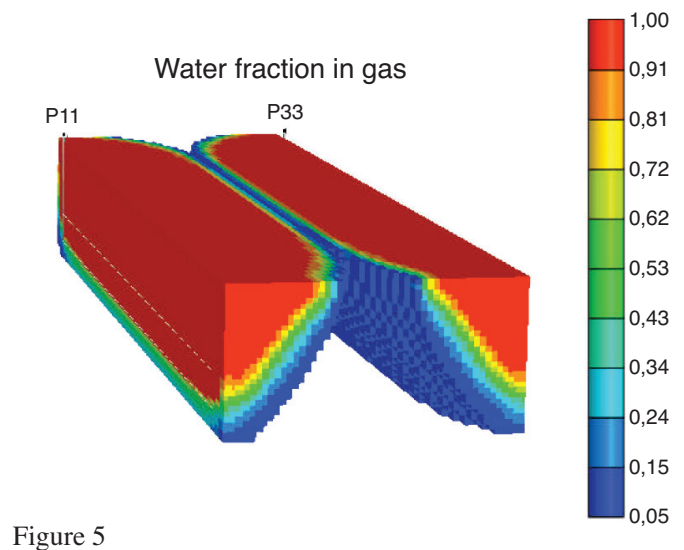

Water fraction $(>5 \%)$ in gas after 9 years of steam injection.

Flow simulations are performed for all of these realizations reproducing the same production history as the one described above, that is a SAGD phase in a depleted environment followed by a blow down. As expected, steam was always able to reach the top of the reservoir whatever the shale proportion considered (Fig. 7). 


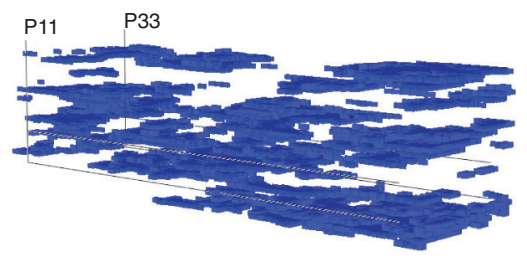

$\mathrm{Vsh}=10 \%$

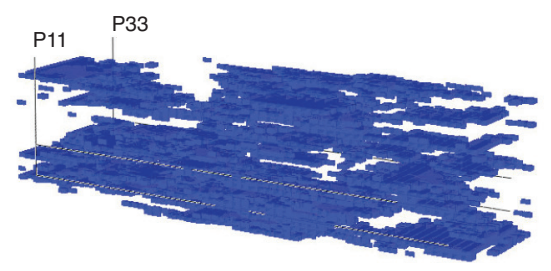

$\operatorname{Vsh}=15 \%$

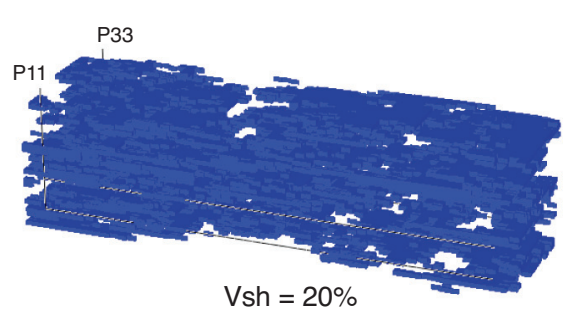

$\mathrm{Vsh}=20 \%$

Figure 6

Examples of shale distributions for proportions of 10, 15 and $20 \%$.

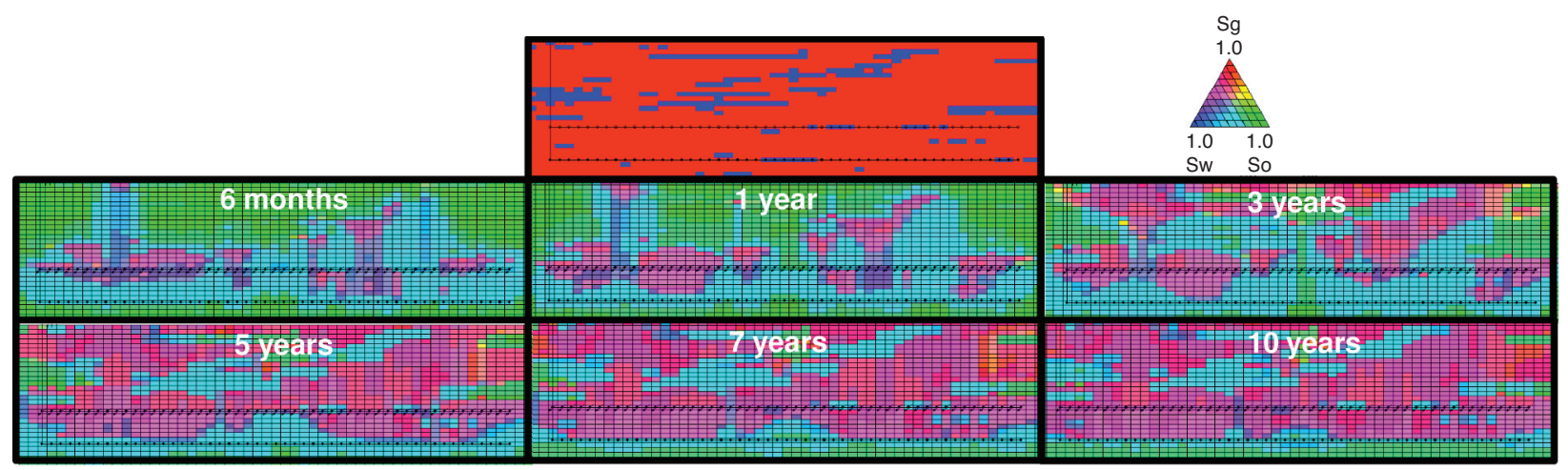

Figure 7

Facies distribution (red: sand; blue: facies) in the vertical slice containing the well pair and the corresponding ternary diagrams at successive injection times.

\subsection{SAGD Performance for a Given Realization}

To investigate the influence of heterogeneity on flow and SAGD process performance, we first consider a given facies realization with $10 \%$ of shale (Fig.7, top) and examine the growth of the steam chamber along well pairs during injection. Steam chamber can be approximately visualized from ternary diagrams captured at different times: it corresponds more or less to the pink zones depicted in Figure 7. A major and obvious difference compared to the homogeneous case is the non uniform chamber development along well length. It can be noticed that the heterogeneities between the wells, even when small, strongly impair chamber development for years. On the other hand, the heterogeneities on the top of the wells break the vertical expansion. However, when vertically stopped, steam moves laterally pretty fast due to the high horizontal permeabilities. Then, it can find a sand path and go around the shale lenses. In the case considered in this subsection, chamber coalescence is observed after 4 years of injection, that is earlier than in the homogeneous case. An earlier coalescence occurs because shale baffles impede the vertical expansion of the steam chamber, but speed up its lateral growth.

The analysis of a few realizations points out that steam chamber expansion mainly depends on the heterogeneities located between the injector and the producer.

\subsection{Statistical Analysis}

In this section, we compare the results obtained for all the realizations. Figure 8 shows the detrimental effect of shale proportion on oil production. Although the same general trends are captured whatever the shale proportions, large differences are stressed during the coming first increasing oil rate period. For the homogeneous base case model, a maximum oil rate of $230 \mathrm{~m}^{3} / \mathrm{d}$ is reached after 2 years of SAGD process. With 10,15 and $20 \%$ of shale, the maximum oil rates decrease to 125,80 and $70 \mathrm{~m}^{3} / \mathrm{d}$. They are reached after 3, 4.5 and 5 years of SAGD recovery, respectively. Therefore, 1/2,1/3 and 1/4 only of the cumulative oil volume produced for the homogeneous model after 3 years of SAGD process are recovered when shale proportions are 10, 15 and $20 \%$ (Tab. 2). The first percents of shale introduced in the reservoir model have the strongest impact; the mean oil rate curves derived for 15 and $20 \%$ of shale are more or less the same. Afterwards, during the decreasing flow rate period, oil rates tend to the values simulated for the homogeneous model. The shale barriers located between the injector and the producer are the first active heterogeneities. They locally inhibit steam chamber development for years. Even 10 years after starting SAGD, fractions of well pairs still do not 


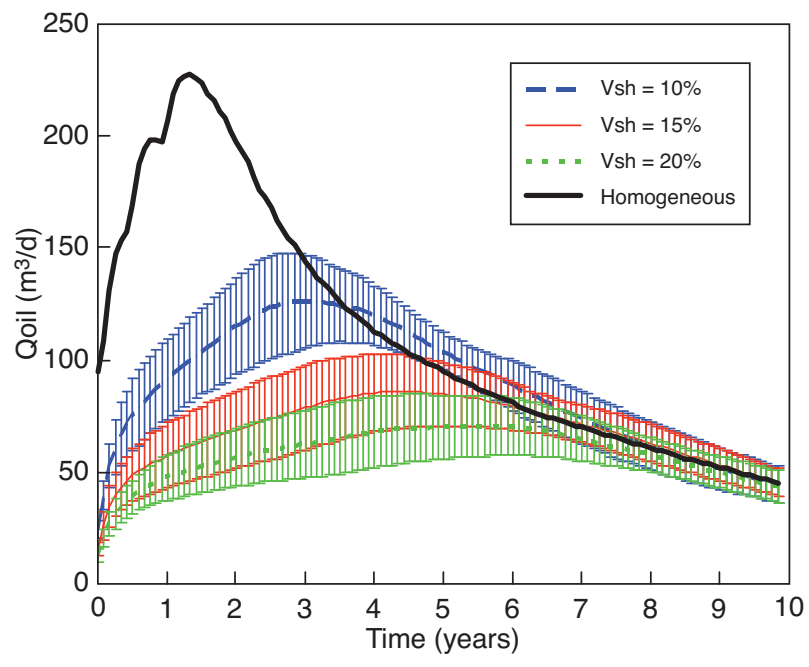

Figure 8

Mean oil rate per well and standard deviation computed for the models with $0,10,15$ and $20 \%$ of shale during the SAGD period.
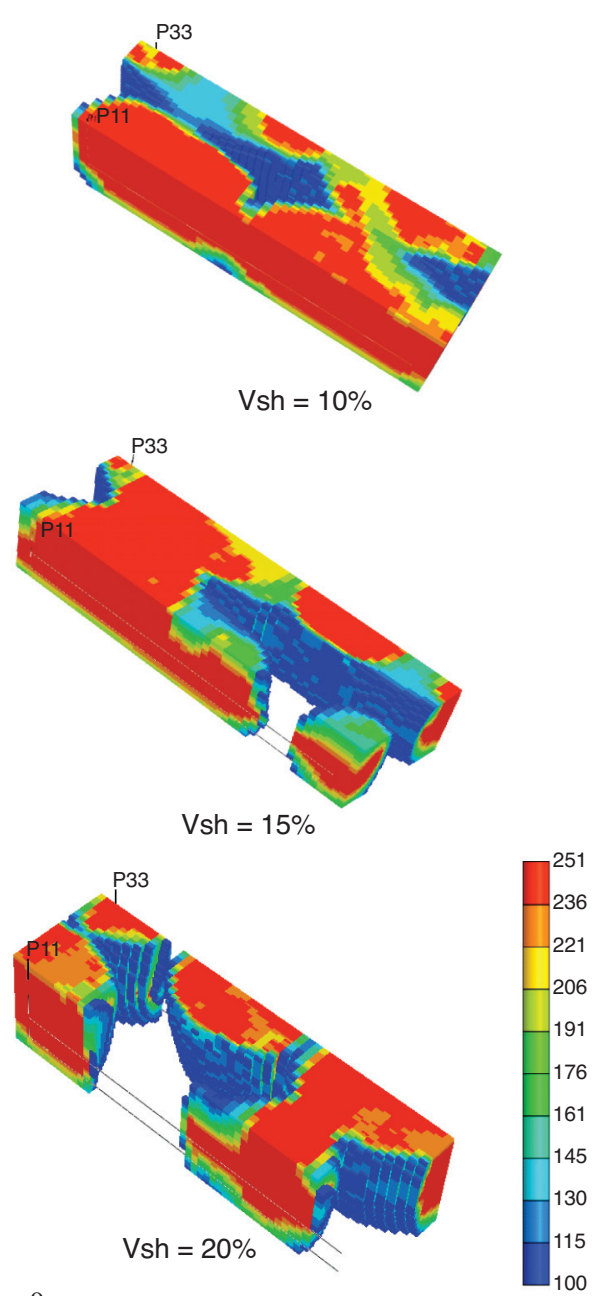

Figure 9

Temperatures greater than $100^{\circ} \mathrm{C}$ after 10 years of SAGD process for realizations with 10,15 and $20 \%$ of shales.

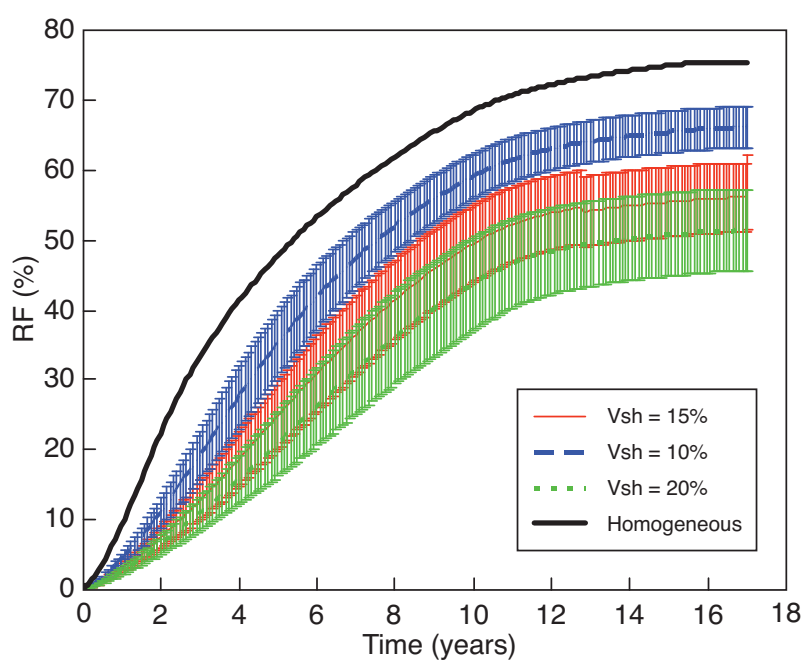

Figure 10

Mean oil recovery factors and standard deviations for shale proportions of $0,10,15$ and $20 \%$ during the SAGD and blowdown periods.

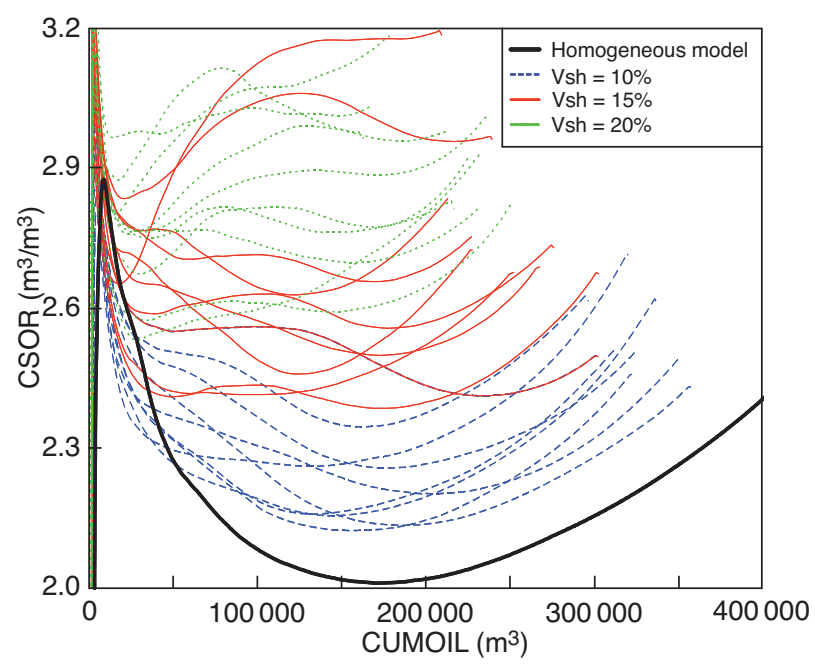

Figure 11

CSOR against cumulative oil volumes produced during SAGD recovery for all the generated realizations.

contribute to production (Fig. 9). Flow barriers above well pairs are less penalizing in the cases considered. First, they are not continuous so that they can be bypassed. Second, they slow down the vertical expansion of the steam chamber, but speed up its lateral growth.

In addition, the oil recovery factors averaged per shale proportion are plotted in Figure 10. Their ultimate values are $75,66,56$ and $52 \%$ for shale proportions of $0,10,15$ and $20 \%$.

SAGD performance is also measured in terms of CSOR. Figure 11 shows that the CSORs estimated for all the generated realizations are roughly stable for a few years 
before starting to increase at the end of the SAGD production period. This last trend is due to the energy balance degradation induced by heat losses. The mean CSOR values evolve from about 2 for the homogeneous model to about 3 for the models with $20 \%$ of shale.

\section{TABLE 2}

Ratios of the mean cumulative oil volumes produced for a given shale proportion to the cumulative oil volume produced for the homogeneous model after 3 and 5 years of SAGD recovery; corresponding mean CSOR.

\begin{tabular}{c|c|c|c|c}
\hline Vsh (\%) & $\begin{array}{c}\text { Mean CUMOIL/ } \\
\text { CUMOIL } \\
(\text { Vsh=0) } \\
\text { @ 3 years (\%) }\end{array}$ & $\begin{array}{c}\text { Mean CUMOIL/ } \\
\text { CUMOIL } \\
\text { (Vsh=0) } \\
\text { @ years }(\%)\end{array}$ & $\begin{array}{c}\text { Mean CSOR } \\
\text { @ 3 years } \\
\left(\mathrm{m}^{3} / \mathrm{m}^{3}\right)\end{array}$ & $\begin{array}{c}\text { Mean CSOR } \\
@ \text { 5 years } \\
\left(\mathrm{m}^{3} / \mathrm{m}^{3}\right)\end{array}$ \\
\hline 0 & 100 & 100 & 2,0 & 2,1 \\
\hline 10 & 53 & 67 & 2,3 & 2,3 \\
\hline 15 & 32 & 44 & 2,7 & 2,6 \\
\hline 20 & 27 & 36 & 2,8 & 2,9 \\
\hline
\end{tabular}

\section{CONCLUSIONS}

In this paper, we report the results of a sensitivity analysis performed to quantify the impact of reservoir heterogeneity on SAGD process performance in mobile heavy oil reservoirs. Oil production is simulated for three sets of reservoir models with shale proportions of 10,15 and $20 \%$ and is compared to the results computed for the homogeneous base case model. Controlling shale proportions allows for varying continuity of shale baffles. The following conclusions are stressed:

- the impact of shale baffles on oil production depends on their locations relatively to well pairs;

- if they are located in between the injector and producer, even when small and discontinuous, they are the first heterogeneities to affect steam chamber development. They locally inhibit steam chamber initiation for years. Even 10 years after starting SAGD, some fractions of the well pairs do not have steam chamber development;

- shale heterogeneities above well pairs are less damaging for production. First, they are not continuous, which means that they can be bypassed. Second, although they slow down the vertical expansion of the steam chamber, they speed up its lateral growth;
- $1 / 2,1 / 3$ and $1 / 4$ only of the cumulative oil volume produced for the homogeneous model after 3 years of SAGD process are recovered when shale proportions are 10,15 and $20 \%$;

- CSOR evolves from 2 for the homogeneous model to 3 for the models with $20 \%$ of shale.

\section{REFERENCES}

Albahlani A.M., Babadagli T. (2008) A critical review of the status of SAGD: where are we and what is next? SPE Western Regional and Pacific section AAPG Joint Meeting, Bakersfield, CA, USA, SPE 113283, 31 March-2 April.

Barillas J.L.M., Dutra T.V., Mata W. (2006) Reservoir and operational parameters influence in SAGD process, J. Petrol. Sci. Eng. 54, 34-42.

Butler R.M. (1991) Thermal recovery of oil and bitumen, Prentice Hall, Englewoods Cliffs, New Jersey, 528 p.

Chen Q., Gerritsen M.G., Kovscek A.R. (2007) Effects of reservoir heterogeneities on the steam-assisted gravity drainage process, SPE ATCE, Anaheim, CA, USA, Nov. 11-14.

Computer Modeling Group Ltd. (2005) STARS ${ }^{T M}$ User Manuals, Calgary, Canada.

Edmunds N.R. (1998) Investigation of SAGD steam trap control in two and three dimensions, SPE Int. Conf. on Horizontal Well Technology, Calgary, Canada, Nov. 4-7.

Edmunds N.R., Haston J.A., Best D.A. (1989) Analysis and implementation of the Steam-Assisted Gravity Drainage Process at the AOSTRA UTF, In Situ Recovery, AOSTRA, pp. 223-238.

Goovaerts P. (1997) Geostatistics for natural ressources evaluation, Oxford University Press, Inc., New York, Oxford.

Jimenez J. (2008) The field performance of SAGD in Canada, IPTC 12860, Kuala Lumpur, Malaysia, Dec. 3-5.

Kisman K.E., Yeung K.C. (1995) Numerical study of the SAGD process in the Burnt Lake Oil Sands Lease, Int. Heavy Oil Symp., Calgary, Alberta, Canada, SPE 30276, 19-21 June.

Stauffer D., Aharony A. (1994) Introduction to percolation theory, Taylor \& Francis, London.

Yang G., Butler R.M. (1992) Effects of reservoir heterogeneities on heavy oil recovery by steam assisted gravity drainage, J. Can. Petrol.Technol.31, 8, 37.

Zhang W., Youn S., Doan Q. (2005) Understanding reservoir architectures and steam chamber growth at Christina Lake, Alberta, by using 4D seismic and crosswell seismic imaging, SPE Int. Thermal Operations \& Heavy Oil Symp., Calgary, Alberta, Canada, SPE/PS-CIM/CHOA 97808, 1-3 November.

Final manuscript received in February 2009 Published online in July 2009 